\title{
Identification of adult males and females of Hoplothrips species (Thysanoptera: Tubulifera) known from Norway, and some deductions on their life history
}

\author{
Sverre Kobro \& Trond Rafoss
}

Kobro, S. \& Rafoss, T. 2006: Identification of adult males and females of Hoplothrips species (Thysanoptera: Tubulifera) known from Norway, and some deductions on their life history. — Entomol. Fennica 17: 184-192.

The presence of multiple phenological forms has previously made adults of Hoplothrips species difficult to identify. We present a set of diagnostic metric characters by which the 8 species recorded from Norway can be recognised. Some biological interpretations are also given.

Sverre Kobro and Trond Rafoss, Bioforsk Plant Health and Plant Protection Division, Høgskoleveien 7, As, N-1432 Norway; correspondent author's e-mail: sverre.kobro@bioforsk.no

Received 25 November 2005, accepted 24 January 2006

\section{Introduction}

Dead trees infected with wood-rotting fungi compose habitats for a rich fauna of specialised insects (Hamilton 1978). Many thrips species, half of the suborder Tubulifera, are associated with dead trees, their bark, dead branches or leaf litter (Palmer \& Mound 1978, Ananthakrishnan 1984). These thrips feed on fungal spores, hyphae or breakdown products from early stages of fungal decay (Mound \& Palmer 1983, Ananthakrishnan 1984) and Hoplothrips species may be characteristic for some of the habitats (Ananthakrishnan 1984). Schliephake and Klimt (1979) noted 11 species from Europe of which two have been synonymised (Vierbergen 2004), while some 130 species are known for the genus world wide (Mound \& Walker 1986).

A fungus infected dead log provides support for numerous generations of Hoplothrips, but over evolutionary time changes in suitability of the habitat have probably selected for differently sized individuals and specialised patterns of breeding structure. Adults of both sexes of the fungivorous thrips can be wingless for several generations and will develop wings only in preparation for dispersal. Thrips species on fungus infected dead trees tend to live gregariously and mate within the habitat, and some of them have developed subsocial behaviour and strong sexual dimorphism (Mound 1974, 1976, Hamilton 1978, Palmer \& Mound 1978). The appearance of oedymerous (major) and gynaecoid (minor) male forms reflects reproductive roles of the males (Hamilton 1978, Crespi 1986). Mound (1974, 1976, 2005) and Hamilton (1978) suggested that the production of different morphs was controlled by the amount or quality of the food ingested by the larvae. The suggestion was confirmed by Crespi (1988) in the Nearctic species Hoplothrips karnyi (Hood). Okajima (1987) on the other hand related growth patterns to the colony size, and Hood (1940) was able to produce either macropterous or micropterous specimens at will by manipulating environmental conditions. Winglessness, polymorphism and gregariousness are 
adaptions to increase the fecundity for fungus foraging thrips on dead wood (Ananthakrishnan 1984, Crespi 1986), and at optimal conditions almost all individuals are micropterous (Hood 1940).

The extreme polymorphism of Hoplothrips adults (Okajima 1987) is probably the reason why identification literature (Priesner 1928, 1964, Morison 1949, Stannard 1957, Mound et al. 1976, Dyadechko 1977, Schliephake \& Klimt 1979, Mound \& Walker 1986, Kirk 1996, Mound \& Marullo 1996) gives no single key character to identify adults in the genus. Moreover, the keys are often based on colour shades or general body characters such as form of the head, body part "a little longer than" etc. and to a lesser extent on exact metric characters. Some of the older descriptions are based upon only one out of several forms, and large and small male forms of the same species have been placed into separate genera (Hood 1955).

Eight species of Hoplothrips are recorded from Norway (Kobro 2001): Hoplothrips carpathicus Pelikán, 1961, Hoplothrips corticis (De Geer, 1773), Hoplothrips fungi (Zetterstedt,1828), Hoplothrips pedicularius (Haliday, 1836), Hoplothrips polysticti (Morison, 1949), Hoplothrips semicaecus (Uzel, 1895), Hoplothrips ulmi (Fabricius, 1781) and Hoplothrips unicolor (Vuillet, 1914). Only H. semicaecus seems to be rare in Norway (Kobro 2003, Olsen \& Solem 1982).

Second stage larvae of $H$. carpathicus, $H$. pedicularius, $H$. polysticti and $H$. ulmi can be discriminated by means of metric characters (Kobro $\&$ Rafoss 2001). The initial objective of this study was to find metric diagnostic characters by which adult specimens of Norwegian species assigned to the genus Hoplothrips could be recognised. We present and discuss a number of such characters to find the most appropriate to use in an identification key. We also discuss their life history as indicated by our study.

\section{Material and methods}

Bark from trunks or branches of dead trees with visible infestation of wood-rotting fungi were investigated for the presence of tubuliferous thrips.
Thrips were recorded from bark infested with Hymenochaete tabacina (Kobro 2003), Pseudospiropes longipilus (Kobro \& Solheim 2002), Stereum spp. (Kobro 2003), Trichaptum abietinum (Kobro 2001) and T. fuscoviolaceus (Kobro 2003). Approximately $0.2-0.3 \mathrm{~m}^{2}$ of bark containing basidiocarps was collected and deposited in Berlese funnels for about a week. Thrips were stored in AGA $(70 \%$ ethanol + glycerol + acetic acid $=10+1+1)$. After storage the specimens were macerated in hot lactic acid or potassium hydroxide, cleared with clove oil and embedded in Canada balsam on glass slides. Most measurements were made at 500× magnification, and only fully extended specimens or body parts were measured.

When possible, 10 adults of each sex of both macropterous and micropterous specimens were selected from different populations and studied. Additionally, if available, a larger number of specimens from single populations of each species were examined. All specimens sampled from the same trunk (usually one sample) were regarded as belonging to the same population. Most specimens examined were collected in Norway. $H$. fungi, $H$. semicaecus and $H$. ulmi were supplemented with 38 specimens (mainly macropterous males, which are rare) borrowed from The Plant Protection Service, Wageningen, The Netherlands and The Natural History Museum, Senckenberg, Germany.

Selection of significant identification characters were based on sample means and standard confidence intervals $(95 \%)$ calculated for all measured characters.

\section{Results}

We have measured or evaluated 53 commonly used characters on a total of 366 adults representing 8 species of Hoplothrips.

The selection of identification characters was based on comparison of confidence intervals calculated from the measurements of the characters measured (Fig.1).

Thirteen characters were chosen according to their utility, as indicated in figure 1 , and used in an identification key for adults of Norwegian Hoplothrips species. 
H. unicolor male micropterus H. unicolor female macropterus $H$. unicolor female micropterus $H$. polysticti male macropterus $H$. carpathicus female macropterus $H$. polysticti male micropterus $H$. polysticti female macropterus $H$. carpathicus male micropterus H. polysticti female micropterus $H$. carpathicus female micropterus $H$. pedicularius male macropterus $H$. pedicularius female macropterus $H$. semicaecus female macropterus $H$. semicaecus male micropterus $H$. semicaecus female micropterus $H$. pedicularius male micropterus $H$. pedicularius female micropterus $H$. fungi female macropterus $H$. fungi female micropterus $H$. fungi male micropterus H. ulmi female macropterus H. ulmi male macropterus $H$. fungi male macropterus H. ulmi male micropterus H. corticis female macropterus H. ulmi female micropterus $H$. corticis male micropterus H. corticis male macropterus $H$. corticis female micropterus $\theta$

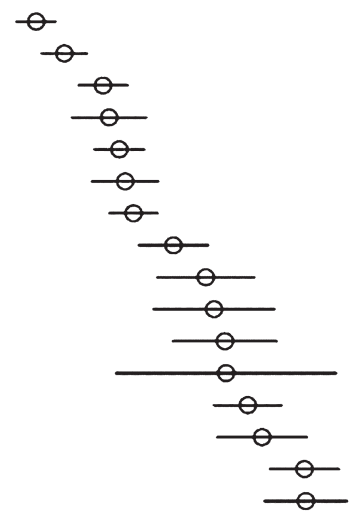

Fig. 1. Illustration of the procedure for selecting of discriminating characters of adults of Hoplothrips species based on sample means and confidence intervals $(95 \%)$ : length $(\mu \mathrm{m})$ of mediolaterale seta on pronotum.

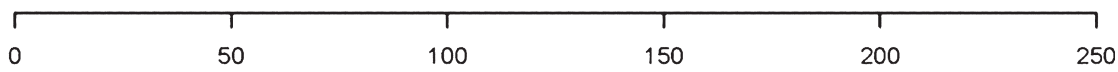

Other examples of the measurements are shown in tables 1-4. A more detailed analysis of the variation in the length of sense cones (multiporous olfactory chemoreceptors) on antennal segment III and the length of medioposteromarginal setae on tergite IX are shown in Figure 2. Posterior prolongation of the fore femora of oedymerous males (Fig. 3), the apices of medioposteromarginal setae on tergite VIII (Fig. 4), and glandular areas on sternite VIII of male $H$. carpathicus (Fig. 5) are shown.

Identification key to the Hoplothrips species recorded in Norway:

1. Mediolateral setae on pronotum shorter than $110 \mu \mathrm{m}$

Mediolateral setae on pronotum longer than $110 \mu \mathrm{m}$

2. Distance between the medioposteromarginal setae on tergite IX the same as or larger than the width of tubus. Anteroangular setae on the margin of pronotum

Hoplothrips unicolor
Distance between the medioposteromarginal setae on tergite IX shorter than the width of tubus. Anteroangular setae at the margin of pronotum

3. Almost always two large sense cones on antennal segment IV

Almost always more than two sense cones on antennal segment IV

4. Distance between bases of antennal segments I larger than $18 \mu \mathrm{m}$. Apical width of antennal segment I larger than $40 \mu \mathrm{m}$. Medioposteromarginal setae on tergite IX longer than $140 \mu \mathrm{m}$. Antennal segment VIII longer than $75 \mu \mathrm{m}$ Hoplothrips carpathicus Distance between bases of antennal segments I less than $18 \mu \mathrm{m}$. Apical width of antennal segment I less than $40 \mu \mathrm{m}$. Medioposteromarginal setae on tergite IX shorter than 125 $\mu \mathrm{m}$. Antennal segment VIII shorter than 75 $\mu \mathrm{m}$

Hoplothrips semicaecus

5. Distance between bases of antennal segments I larger than $16 \mu \mathrm{m}$. Width of antennal segment I larger than $36 \mu \mathrm{m}$. Antennal segment 


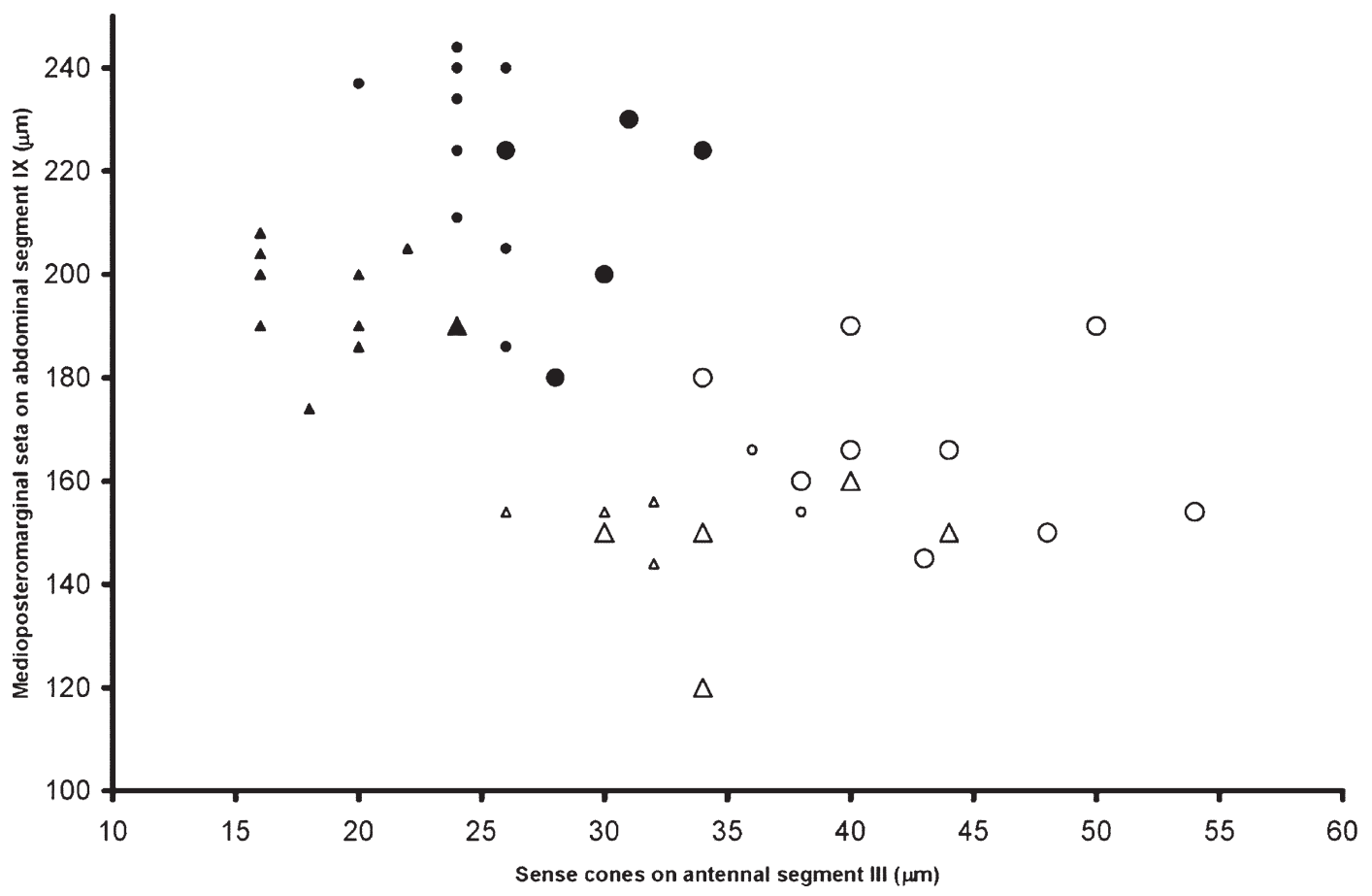

Fig. 2. Combined use of the length of sense cones on antennal segment III and the length of medioposteromarginale seta on abdominal tergite IX for discriminating of adults of Hoplothrips fungi from those of Hoplothrips ulmi and Hoplothrips corticis. $H$. fungi female macropterous $(O), H$. fungi female micropterous (O), $H$. fungi male macropterous $(\triangle), H$. fungi male micropterous $(\triangle) H$. ulmi female macropterous $(\bullet), H$. ulmi female micropterous $(\bullet), H$. ulmi male macropterous $(\boldsymbol{\Delta}), H$. ulmi male micropterous $(\mathbf{\Delta})$.

IV longer than $68 \mu \mathrm{m}$. Medioposteromarginal setae on tergite VIII ending in a very fine tip or open like a suction straw (Fig. 4)

Hoplothrips pedicularius

Distance between bases of antennal segments I less than $16 \mu \mathrm{m}$. Width of antennal segment I shorter than $36 \mu \mathrm{m}$. Antennal segment IV shorter than $68 \mu \mathrm{m}$. Medioposteromarginal setae on tergite VIII evenly tapering

Hoplothrips polysticti

6. Long sense cones (longer than $25 \mu \mathrm{m}$ ) on antennal segment III and short medioposteromarginal setae on abdominal tergite IX (less than $190 \mu \mathrm{m}) \quad$ Hoplothrips fungi Short sense cones (shorter than $35 \mu \mathrm{m}$ ) on antennal segment III and long medioposteromarginal setae on abdominal tergite IX (longer than $170 \mu \mathrm{m}$ )

7. Head broader than long Hoplothrips corticis Head longer than broad

\section{Discussion}

We present estimates and appraisals for metric characters for adults of 8 species of Hoplothrips from Norway, and insert these characters into an identification key.

The size of Hoplothrips adults varies both between and within the species.

Females are larger than the males (Table 1) and the micropterous specimens are larger than the macropterous. Micropterous males vary in size and can be of the large oedymerous form or the smaller gynaecoid form (Hood 1940). Thus, the small males of $H$. polysticti in our study were about half the size of the largest females of H. carpathicus (Table 1). Morison (1949) considered identification to rely mainly on the females, as they are the vary less. Thus, for an entomologist with a single oedymerous male specimen, accurate identification is difficult.

The characters we studied can be separated in 
Table 1. Average total body length $(\mathrm{mm})$ of male $(\mathrm{m})$ and female $(\mathrm{f})$ micropterae.

\begin{tabular}{llllllll}
\hline & \multicolumn{3}{c}{ Single population } & & \multicolumn{3}{c}{ Several populations } \\
\cline { 2 - 4 } & $\mathrm{n}$ & $\mu \mathrm{m}$ & S.D. & & $\mathrm{n}$ & $\mu \mathrm{m}$ & S.D. \\
\hline H. carpathicus $\mathrm{f}$ & 11 & 3.4 & 0.1 & & 7 & 3.4 & 0.3 \\
H. carpathicus $\mathrm{m}$ & 32 & 2.7 & 0.2 & & 4 & 2.7 & 0.1 \\
H. pedicularius $\mathrm{f}$ & 10 & 3.2 & 0.2 & & 9 & 3.0 & 0.2 \\
H. pedicularius $\mathrm{m}$ & 32 & 2.6 & 0.2 & & 9 & 2.4 & 0.2 \\
H. polystictif & 21 & 2.8 & 0.1 & & 10 & 2.7 & 0.1 \\
H. polysticti $\mathrm{m}$ & 17 & 2.0 & 0.2 & & 10 & 1.9 & 0.1 \\
\hline
\end{tabular}

Table 2. Average length $(\mu \mathrm{m})$ of mediolaterale seta on pronotum of male $(\mathrm{m})$ and female (f).

\begin{tabular}{lrrrrrrr}
\hline & \multicolumn{3}{c}{ Single population } & & \multicolumn{3}{c}{ Several populations } \\
\cline { 2 - 4 } \cline { 5 - 7 } & $\mathrm{n}$ & $\mu \mathrm{m}$ & S.D. & & $\mathrm{n}$ & $\mu \mathrm{m}$ & S.D. \\
\hline H. corticis $\mathrm{f}$ & 8 & 203 & 12 & & 10 & 204 & 24 \\
H. corticis $\mathrm{m}$ & 6 & 197 & 8 & & 10 & 194 & 13 \\
H. carpathicus $\mathrm{f}$ & 11 & 60 & 12 & & 10 & 69 & 16 \\
H. carpathicus $\mathrm{m}$ & 31 & 56 & 7 & 10 & 52 & 8 \\
H. pedicularius $\mathrm{f}$ & 10 & 90 & 8 & 10 & 92 & 14 \\
H. pedicularius $\mathrm{m}$ & 32 & 89 & 10 & & 10 & 92 & 11 \\
H. polystictif & 21 & 71 & 10 & & 10 & 62 & 11 \\
H. polysticti m & 17 & 55 & 8 & 10 & 49 & 8 \\
\hline
\end{tabular}

several groups. Most of the characters examined are positively correlated with body length in a general allometric pattern regardless of sex and morph. Some characters however, are not correlated to the body length. Despite males being smaller than females, a number of characters are larger in males. Such characters include the length of the pronotum, the fore tarsal tooth

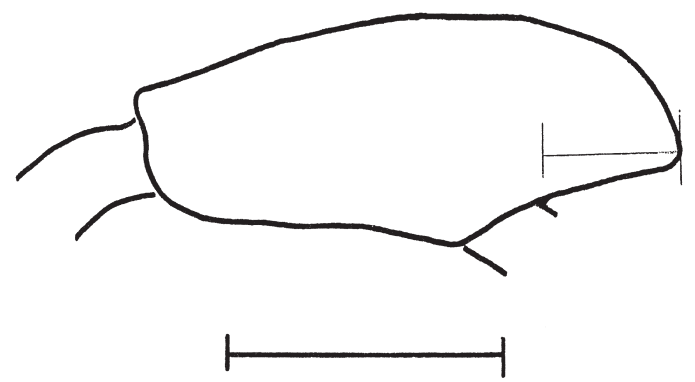

Fig. 3. Posterior prolongation of fore femur indicated with a thin bar. Thick bar $100 \mu \mathrm{m}$. length and width, fore femur length and width and the most striking external male character which is the posterior prolongation of the fore femur (Fig. 3). Variation in length of this prolongation in fore femur of three of the species is shown in table 3 . These characters vary considerably within some species, as indicated by the high standard deviations and may be particularly important for defence of the oviposition site and females and is expressed most in oedymerous males of $H$. pedicularius (Crespi 1986). If accepted as an indicator of behaviour, variation in size of these characters within our material indicates that the males of $H$. corticis, $H$. fungi, $H$. semicaecus and $H$. ulmi have an aggressive behaviour similar to that of $H$. pedicularius, i.e. they defend resources such as oviposition sites and mated females. By the same argument, the species $H$. polysticti and $H$. unicolor, are more "peaceful" as their males are not equipped for fighting, while males of $H$. carpathicus are inter- 
Table 3. Average length $(\mu \mathrm{m})$ of posterior prolongation of fore femur of micropterae male $(\mathrm{m})$ and female $(\mathrm{f})$.

\begin{tabular}{lccrrrrr}
\hline & \multicolumn{3}{c}{ Single population } & & \multicolumn{3}{c}{ Several populations } \\
\cline { 2 - 4 } \cline { 6 - 8 } & $\mathrm{n}$ & $\mu \mathrm{m}$ & S.D. & & $\mathrm{n}$ & $\mu \mathrm{m}$ & S.D. \\
\hline H. carpathicus $\mathrm{f}$ & 10 & 26 & 7 & 10 & 34 & 15 \\
H. carpathicus $\mathrm{m}$ & 31 & 35 & 14 & & 10 & 44 & 16 \\
H. pedicularius $\mathrm{f}$ & 10 & 33 & 8 & & 10 & 41 & 6 \\
H. pedicularius $\mathrm{m}$ & 32 & 74 & 25 & & 10 & 91 & 28 \\
H. polystictif & 22 & 20 & 3 & & 10 & 20 & 5 \\
H. polysticti $\mathrm{m}$ & 17 & 18 & 5 & & 10 & 21 & 8 \\
\hline
\end{tabular}

mediate in this respect. However, experimental evidence for the association between body size and defence is lacking for these species (Mound 2005).

The conspicuous characteristics of the oedymerous micropterous males make identification difficult and these characters are avoided in our identification key. The characters we have selected are typical for adult Hoplothrips species regardless of sex or morph.

The number of sense cones on antennal segment III and IV is commonly used for identification of tubuliferans (Schliephake \& Klimt 1979, Mound \& Walker 1986). In our material of Hoplothrips this character is constant only in $H$. carpathicus and $H$. semicaecus. The number of sense cones is particularly variable in $H$. polysticti where antennal segment III can have 2-3 (rarely 1) and antennal segment IV 3-4 (rarely 2) sense cones. Relying too much on the number of sense cones therefore makes identification ineffective. The number of sense cones varies within Hoplothrips species in other parts of the world and also in species of Deplorothrips and Psiladothrips (Mound \& Walker 1986).

Mound et al. (1976) and Kirk (1996) considered rounded apices of medioposteromarginal setae on tergite VIII as characteristic for $H$. pedicularius. This character was ambiguous for our material, as these setae can be very sharply pointed; where a thin tip can break and make the apex look rounded or more often open like a drinking straw (Fig. 4) but never expanded as in H. semiceacus (Mound et al. 1976).

Of the allometric characters examined, the length of mediolateral setae on the pronotum is the most useful in separating adults of Hoplo-
Table 4. Relative length of the head of $H$. corticis and H. ulmi $(p<0.0001)$.

\begin{tabular}{lccc}
\hline & $\mathrm{n}$ & Mean & S.D. \\
\hline Hoplothrips corticis & 19 & 0.94 & 0.03 \\
Hoplothrips ulmi & 13 & 1.07 & 0.04 \\
\hline
\end{tabular}

thrips species into two distinct groups (Fig. 1). In one group the three species $H$. corticis, $H$. fungi and $H$. ulmi are closely related (Mound et al. 1976). The combined use of the length of the sense cones on antennal segment III and the length of medioposteromarginal setae on abdominal tergite IX to distinguish $H$. ulmi and $H$. fungi (Mound et al. 1976) is verified by us (Fig. 2). Based on this character, $H$. corticis is in the same group as H. ulmi, but these two species can be distinguished by the proportions of their heads: the head of $H$. corticis is broader than long, while that of $H$. ulmi is longer than broad (Table 4).

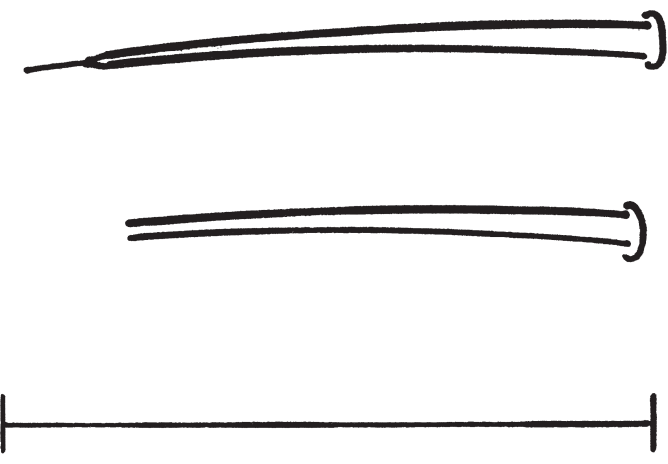

Fig. 4. Medioposteromarginal seta on abdominal tergite VIII with pointed or open apex. Bar $100 \mu \mathrm{m}$. 
Adults of the 5 species in the other group can be discriminated by single characters. More than one character is given at several steps in the key even if one is conclusive, in case they will be needed if more species are added to the key in the future.

Lewis (1973) used the term brachypterous for specimens with wings of reduced size. The small wings of the Hoplothrips species are so minute that they are easily overlooked, and micropterous (Hood 1940, Mound 2005, Mound \& Marullo 1996, Mound \& Walker 1986) is a more appropriate term. In two species, H. semicaecus and $H$. unicolor, the wings are rudimentary (only 1-2 micrometers long), while in $H$. carpathicus we found a continuous transition between rudimentary wings and small wing pads. We refer to all these as micropterous.

Winglessness increases fecundity (Crespi 1986), as producing wings only when necessary saves energy. In macropterous forms of Hoplothrips however, wings are produced but are often broken off at a characteristic position. Flimsy wing structures appear to be functional adaptations to the leaf litter habitats (Ananthakrishnan 1984), are called caducous and are typical for the habitat (Hamilton 1978). We have observed broken wings and a breakage zone distally to the subbasal setae in wings of macropters of all species studied here, most frequently in $H$. carpathicus, $H$. pedicularius and H. polysticti. Moritz (2002) suggested the wing breakage to result from copulation and to prevent further matings with other males. Dominant males defend a number of females at an oviposition site (Crespi 1986), and the wing breakage might be another way to keep the females within the harem.

It is very difficult to identify adult female at genus level by using traditional criteria (Mound et al. 1976, Palmer \& Mound 1978, Ananthakrishnan 1984). All macropterous specimens of Hoplothrips in our material have two sub-basal setae on the fore-wings in contrast to those of most other genera of Phlaeothripinae. The character is of limited value, however, as the micropterous form, in which the sub-basal setae can be absent or difficult to see, predominates. Males can be recognised at the genus level by the form of the glandular area on sternite VIII. Good figures are given in Mound et al. (1976) and Mound

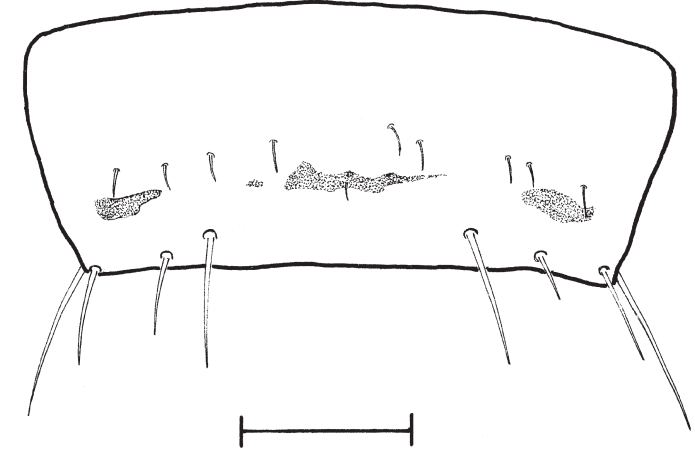

Fig. 5. Sternite VIII on Hoplothrips carpathicus. Bar $100 \mu \mathrm{m}$.

\& Walker (1986), except for H. carpathicus which is figured here (Fig. 5).

Despite the fact that Hoplothrips species having been regarded as difficult to identify due to their morphological variation, several of the Norwegian species are easily distinguishable by "macroscopic" characters visible without preparation, given some experience and that they are collected on dead wood. $H$. corticis, $H$. fungi and H. ulmi superficially resemble Phlaeothrips annulipes O. M. Reuter, 1880 and are more difficult to identify, even if $H$. corticis can be recognised by its cheeks appearing more swollen behind the eyes and their tibiae are usually yellow. The 5 other species of Hoplothrips are different and relatively easy to recognise. Adults of $H$. carpathicus are large (Table 1) and one-coloured greyish-brown, and are rarely recorded unless bark is removed with an axe from large dead birches (Kobro \& Solheim 2002). Those of H. pedicularius are also large and mainly dark brown with a light yellow gore posterior on the abdomen, while micropterous specimens also have bright yellow forelegs and head. Adults of $H$. polysticti have about the same colour as $H$. carpathicus, but are much smaller (Table 3 ), with the head often square. H. semicaecus adults have antennal segments VII and VIII broadly fused. The antennal segments are of contrasting colour: segments I-III are yellow, while the other segments are darker than the rest of the body. $H$. unicolor adults are small, light brown and with darker brown cross bands on the abdominal segments, which fade during preparation.

Norwegian Hoplothrips species live on fungi 
on larger branches or trunks of dead shrubs and trees, which appear scattered in time and space and are termed ephemeral habitats (Hanski 1987). These trunks and branches persist for a long time and can support fungivorous thrips for several generations. We have observed such habitats to persist for years. One log of Norway spruce, Picea abies, was storm felled in 1992 and still supported reproduction of $H$. polysticti in 2002, when several females with broken wings were collected. In 1999 H. carpathicus was collected from a tall dead birch and the number of specimens developing that year was calculated to be 2700 (Kobro \& Solheim 2002). The tree had probably already been inhabited by thrips for several years. It still supported growth of thrips and at present there is no sign of an impending deterioration of that habitat. Sooner or later the habitat will be exhausted as a substrate for the fungus. Then the thrips have to disperse to other appropriate fungus infected dead wood. This is probably why these species occur in scattered local populations (Hanski \& Simberloff 1997).

One could ask whether the variation in characters within a species is evenly distributed between the scattered local populations. To answer this question, specimens selected from several distant populations were compared with a number of specimens from one population. There was no striking difference indicated by averages and standard deviations as shown in the tables 1-3. However, the average length of the posterior prolongation of fore femur seemed to be larger when the measured specimens were selected from several populations of $H$. carpathicus and $H$. pedicularius (Table 5). This difference is most likely an artefact as the selection of specimens was not unbiased; it is easy to choose the larger ones. Hence, the values calculated from specimens from a single population better describe the species, underlining the importance of care when selecting characters for an identification key.

Acknowledgements. We are most thankful to Nina Trandem and Geir K. Knudsen for reviewing a draft to this manuscript, Bert Vierbergen and Richard zur Strassen for lending us specimens. We also thank Richard zur Strassen for critical remarks on the identification key. Additionally we thank Gry Alfredsen and Halvor Solheim for identification of the fungi.

\section{References}

Ananthakrishnan, T. N. 1984: Bioecology of thrips. Indira Publishing House, Oak Park, Michigan, USA. $229 \mathrm{pp}$.

Crespi, B. J. 1986: Territoriality and fighting in a colonial thrips, Hoplothrips pedicularius, and sexual dimorphism in Thysanoptera. - Ecol. Entmol. 11: 119-130.

Crespi, B. J. 1988: Adaptation, compromise, and constraint: the development, morphometrics, and behavioural basis of a fighter-flier polymorphism in male Hoplothrips karnyi (Insecta: Thysanoptera) - Behav. Ecol. Sociobiol. 23: 93-104.

Dyadechko, N. P. 1977: Thrips or Fringe-Winged Insects (Thysanoptera) of the European Part of the USSR. Armerind Publishing Co. Pvt. Ltd., New Dehli. 344 pp.

Hamilton, W. D. 1978: Evolution and diversity under bark. — In: Mound, L. A. \& Waloff, N. (eds.), Diversity of Insect Faunas: 154-187. The Royal Entomological Society, Blackwell Scientific Publications, Oxford, London, Edinburgh, Melbourne. 204 pp.

Hanski, I. 1987: Colonization of ephemeral habitats. - In Gray, A.J., Crawley, M.J. \& Edwards, P.J. (eds.), Colonization, succession and stability: 155-183. Blackwell Scientific Publication, Oxford. 482 pp.

Hanski, I. \& Simberloff, D. 1997: The metapopulation approach, its history, conceptual domain, and application to conservation. - In Hanski, I. \& Gilpin, M. E. (eds.), Metapopulation biology: ecology, genetics and evolution: 5-26. Academic Press. 512 pp.

Hood, J. D. 1940: The cause and significance of macropterism and brachypterism in certain Thysanoptera, with description of a new species. - An. Cien. Biol. (Mexico) 1: 497-505.

Hood, J. D. 1955: Anew Hoplothrips (Thysanoptera) from Florida. - Fla. Entomol. 38(1): 27-32.

Kirk, W. D. J. 1996: Thrips. Naturalists' handbooks 25. The Richmond Publishing Co. Ltd. England. 70 pp.

Kobro, S. 2001: Hoplothrips polysticti (Thysanoptera) on the wood-rotting polypore Trichaptum abietinum infesting dead Picea abies in Norway. - Entomol. Fennica 12: 15-21.

Kobro, S. 2003: On the Norwegian thrips fauna (Thysanoptera). - Norw. J. Entomol. 50: 17-32.

Kobro, S. \& Rafoss, T. 2001: Diagnostic characters of the larvae of some Hoplothrips species (Thysanoptera: Tubulifera) in Norway. — Eur. J. Entomol. 98: 543546.

Kobro, S. \& Solheim, H. 2002: Hoplothrips carpathicus Pelikán, 1961 (Thysanoptera, Phlaeothripidae) in Norway. - Norw. J. Entomol. 49: 143-144.

Lewis, T. 1973: Thrips, their biology, ecology and economic importance. - Academic press, London and New York. 349 pp.

Morison, G. D. 1949: Thysanoptera of the London area. Part 11l. Key to the British genera and species of Thysanoptera (contd.). - The Naturalist: the Journal of the 
London Natural History Society, Year 1948. 28: 77131.

Moritz, G. 2002: The biology of thrips is not the biology of their adults: a developmental view. - In: Marullo R. \& Mound L. A. (eds.), Thrips and tospoviruses: Proceedings of the $7^{\text {th }}$ international symposium on Thysanoptera: 259-267. Aust. Natl. Insect Collect., Canberra. $390 \mathrm{pp}$.

Mound, L. A. 1974: The Nesothrips complex of spore feeding Thysanoptera (Phlaeothripidae: Idolothripinae). - Bull. Br. Mus. Nat. Hist. Ent. 31 No 5, London. 188 pp.

Mound, L. A. 1976: American leaf-litter Thysanoptera of the genera Erkosothrips, Euythrips and Terthrothrips (Phlaeothripidae: Phlaeothripinae). — Bull. Br. Mus. Nat. Hist. Ent. 35 No 2, London. 64 pp.

Mound, L. A. 2005: Thysanoptera: diversity and interactions. - Annu. Rev. Entomol. 50: 247-269.

Mound, L. A. \& Palmer, J. M.1983: The generic and tribal classification of spore-feeding Thysanoptera (Plaeothripidae: Idolothripidae). - Bull. Br. Mus. Nat. Hist. Ent. 46 No 1, London. 174 pp.

Mound, L. A. \& Walker, A. K. 1986: Tubulifera (Insecta: Thysanoptera). - Fauna of New Zealand 10.140 pp.

Mound, L. A. \& Marullo, R. 1996: The thrips of central and south America: an introduction (Insecta: Thysanoptera). - Associated Publishers, Gainesville, USA. $487 \mathrm{pp}$.

Mound, L. A., Morison, G. D., Pitkin, B. R., and Palmer, J.
M. 1976: Handbooks for the identification of British insects. Vol. 1, Part 11. - Thysanoptera. Royal Entomological Society of London. 79 pp.

Okajima, S. 1987: Studies on the Old World species of Hoplothrips (Thysanoptera: Phlaeothripidae). Bull. Br. Mus. Nat. Hist. Ent. 54 No 1, London. 74 pp.

Olsen, A. \& Solem, J. O. 1982: On the Norwegian thrips fauna (Thysanoptera). - Fauna Norv. Ser. B 29: 5-16.

Palmer, J. M. \& Mound, L. A. 1978: Nine genera of fungus-feeding Phlaeothripidae (Thysanoptera) from the Oriental Region. - Bull. Br. Mus. Nat. Hist. Ent. 37 No 5, London. 215 pp.

Priesner, H. 1928: Die Thysanopteren Europas. — Verlag von Fritz Wagner, Wien. 755 pp.

Priesner, H. 1964: Ordnung Thysanoptera (Fransenflügler, Thripse). - Akademie-Verlag, Berlin. 242 pp.

Schliephake, G. \& Klimt, K. 1979: Thysanoptera, Fransenflügler. Die Tierwelt Deutschlands, 66. — VEB Gustav Fisher Verlag, Jena. 475 pp.

Stannard, L. J. 1957: The phylogeny and classification of the North American genera of the suborder Tubulifera (Thysanoptera). - Illinois biological monographs: no. 25. The University of Illinois press, Urbana. 167 pp.

Vierbergen, G. 2004: Eight species of thrips new for The Netherlands and some taxonomical changes in Stenochaetothrips, Thrips and Hoplothrips (Thysanoptera). — Acta Phytopathol. Entomol. Hung. 39 (1-3): 199209. 